Article

\title{
Study on Fabrication and Properties of Graphite/Al Composites by Hot Isostatic Pressing-Rolling Process
}

\author{
Hao Jia ${ }^{1,2}$, Jianzhong Fan ${ }^{1, *}$, Yanqiang Liu ${ }^{1,3, *}$, Yuehong Zhao ${ }^{1}$, Junhui Nie ${ }^{1,3}$ and Shaohua Wei ${ }^{1}$ \\ 1 GRINM Metal Composites Technology Co. Ltd., Beijing 101407, China; chinsland@sina.com (H.J.); \\ 18612186108@163.com (Y.Z.); niejunkey@163.com (J.N.); weishaohua666@163.com (S.W.) \\ 2 General Research Institute for Non-Ferrous Metals, Beijing 100088, China \\ 3 GRIMAT Engineering Institute Co., Ltd., Beijing 101407, China \\ * Correspondence: jzfan@grinm.com (J.F.); liuyanqiang@grinm.com (Y.L.)
}

check for updates

Citation: Jia, H.; Fan, J.; Liu, Y.; Zhao,

Y.; Nie, J.; Wei, S. Study on

Fabrication and Properties of Graphite/Al Composites by Hot Isostatic Pressing-Rolling Process. Materials 2021, 14, 2522. https:// doi.org/10.3390/ma14102522

Academic Editor: Pavel Lukáč

Received: 29 March 2021

Accepted: 8 May 2021

Published: 12 May 2021

Publisher's Note: MDPI stays neutral with regard to jurisdictional claims in published maps and institutional affiliations.

Copyright: (c) 2021 by the authors. Licensee MDPI, Basel, Switzerland. This article is an open access article distributed under the terms and conditions of the Creative Commons Attribution (CC BY) license (https:// creativecommons.org/licenses/by/ $4.0 /)$.

\begin{abstract}
Graphite/Al composites have attracted much attrition due to their excellent thermal properties. However, the improvement of thermal conductivity (TC) is limited by the difficulty in controlling the orientation of graphite and the poor wettability between graphite and aluminum. In this study, a novel process for fabricating the Graphite/Al composites is proposed, which involves fabricating graphite film and aluminum foil into laminate material. Then, taking a rolling method, the fractured and well oriented graphite film can help the composite achieve high TC while maintaining a certain strength. The result reveals that both single and total reduction have a significant influence on the diameter and orientation of the graphite, and by adjusting the process parameters, composites with high TC can be acquired at a relatively low reinforcement volume. This near-net-forming process can directly meet the thickness requirements for electronic packaging and avoids the exposure of graphite to the surface during secondary processing, which is promising to promote the application for high TC Graphite/Al composites in thermal management.
\end{abstract}

Keywords: graphite film; metallic composites; thermal properties; rolling

\section{Introduction}

With the rapid development of electronic devices towards miniaturization, lightweight, and high performance, the heat produced by the ever-increasing power density has become a key problem in restricting the reliability and efficiency of electronic equipment [1,2]. In order to effectively dissipate heat, the thermal management materials with high thermal conductivity (TC) and low coefficient of thermal expansion (CTE) which matches to the semiconductors are urgently needed. To date, thermal management materials have been developed for several periods, but some traditional thermal management materials, such as Invar, Kovar, $\mathrm{SiC} / \mathrm{Al}$, and $\mathrm{Si} / \mathrm{Al}$, can no longer fulfill the requirements for high power electronic devices due to insufficient TC [3,4]. In recent years, metal matrix composites (MMCs) reinforced by carbon materials, including carbon fibers [5,6], graphite, diamond $[7,8]$, carbon nanotubes (CNTs) [9,10], and graphene [11], have become promising materials for thermal management applications due to their high TC and low density.

In the previous study, some works have been done as a result to combine graphite with metal composite through different processes. Take graphite flake (Gf) as an example, Ouyang et al. [12] obtained the $50 \mathrm{vol} \%$ Gf reinforced composite by powder metallurgy, which had TC of $555 \mathrm{~W} / \mathrm{m} \cdot \mathrm{K}$. Li et al. [13] manufactured $70 \mathrm{vol} \% \mathrm{Gf} / \mathrm{Al}$ composites with preferred orientation and the TC reached $714 \mathrm{~W} / \mathrm{m} \cdot \mathrm{K}$. However, the flexural strength is less than $20 \mathrm{MPa}$, and due to the brittleness of graphite, increasing the volume fraction will inevitably lead to a decline in mechanical properties, so it is essential to achieve high TC with a relative low reinforcement volume so that the composite can maintain good mechanical properties. 
In order to maximize the high TC of graphite materials and promote the application of Graphite/ $\mathrm{Al}$ composite, there are still several problems that need to be solved. It is well known that poor wettability and interfacial reaction which produces $\mathrm{Al}_{4} \mathrm{C}_{3}$ between aluminum and graphite were harmful for the thermal stability, mechanical properties, and stacking of graphite leaves almost no space between the flakes, which make liquid metal difficult to infiltration in [14]. Besides, to take advantage of the anisotropic thermal properties of graphite, it is very important to control the orientation of graphite [15].

Recently, artificial graphite films fabricated from polyimide films have attracted much attention in thermal management applications due to their high graphitization degree and high TC [2,9]. The in-plane TC of graphite film can reach 1100-1600 W/m·k, which is much higher than that of graphite flake. Based on this, Huang et al. $[16,17]$ used graphite films and aluminum foils as raw materials and fabricated laminate composites by vacuum hot pressing. Having successfully solved the problem on orientation, the TC of obtained composites can reach as high as $902 \mathrm{~W} / \mathrm{m} \cdot \mathrm{K}$. Nevertheless, its application was still restricted by low mechanical properties, and research shows that mechanical properties are closely related to the diameter of graphite [18]. When the load was applied, crack propagation more easily occurred on graphite to a great extent. In order to make up for the deficiency of laminated materials, the rolling process, which has been widely used in configuration controlling and interlayer bonding $[19,20]$, was proposed in this study. And the SiC coating was grown on the surface of graphite film by molten salt method to improve its interfacial bonding with $\mathrm{Al}$. The preparation sketch of the composites is shown in Figure 1. The fractured and well-oriented graphite film is helpful to maintain the high TC of the composites, meanwhile, the discontinuous structure can make full use of the strengthening effect of the metal matrix on the mechanical properties. The effects of process parameters on microstructure and properties of the composites were mainly investigated.

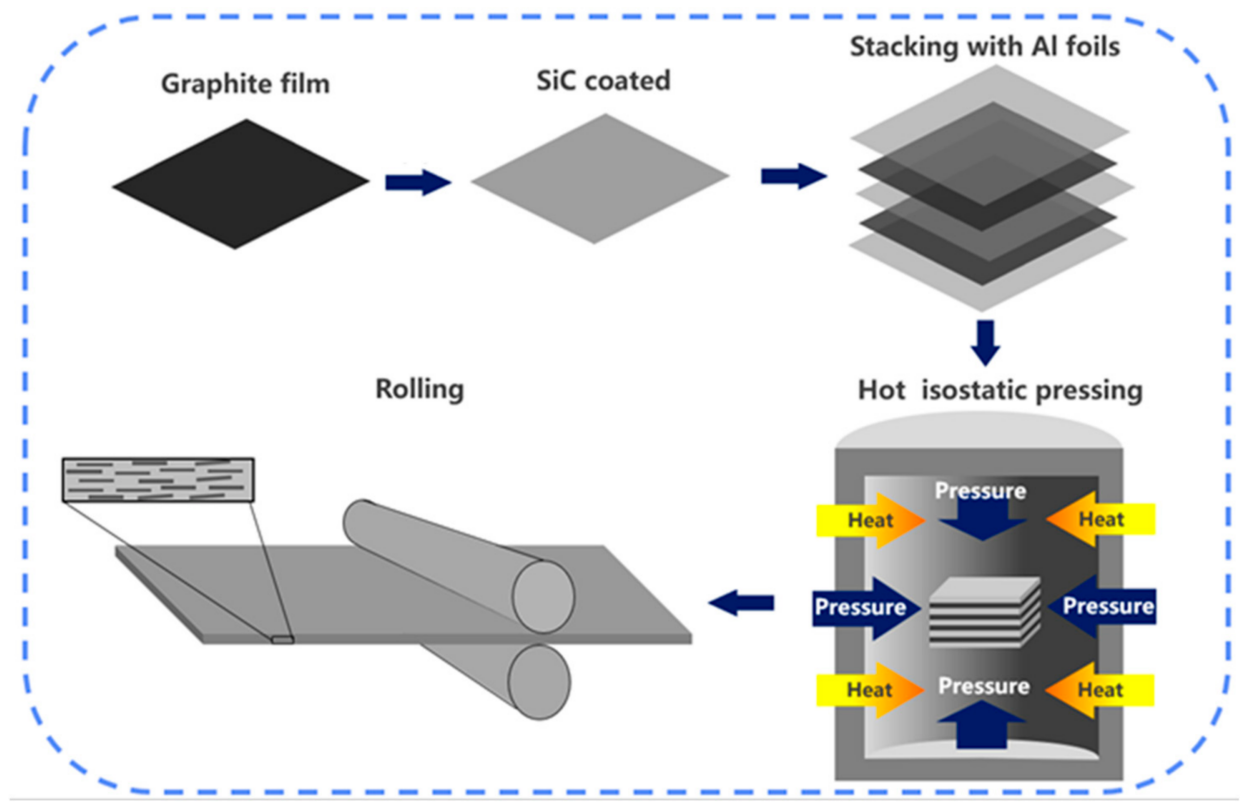

Figure 1. Fabrication process for graphite film/aluminum composites.

\section{Materials and Methods}

\subsection{Raw Materials}

Graphite films and pure $\mathrm{Al} 1060$ foils (99.6\% in purity, with TC of $234 \mathrm{~W} / \mathrm{m} \cdot \mathrm{K})$ were used as raw materials. Al foils with thickness of $50 \mu \mathrm{m}$ ware purchased from Shanghai Yuanyi metals Co.Ltd (Shanghai, China). The graphite films with average thickness of $25 \mu \mathrm{m}$ were acquired from Tanyuantech Co., Ltd. (Changzhou, China). The in-plane and out-of-plane TC of the graphite films were measured to be $1258 \mathrm{~W} / \mathrm{m} \cdot \mathrm{K}$ and $18 \mathrm{~W} / \mathrm{m} \cdot \mathrm{K}$, respectively. 


\subsection{Preparation of the Composites}

$\mathrm{NaCl}, \mathrm{KCl}$ and Si powder (with the mass ratio of 4: 4: 1) was put into a mixing bowl and stirred in a two-dimensions mixer for $8 \mathrm{~h}$ at $200 \mathrm{rpm}$. Then the graphite films with mixed powder covered on the surface were set into a corundum crucible, and placed in the vacuum induction furnace, heated from $25^{\circ} \mathrm{C}$ to $1150{ }^{\circ} \mathrm{C}$ in a vacuum induction furnace, and kept for $120 \mathrm{~min}$ in an argon atmosphere. After treatment, the coated graphite was cleaned in deionized water and dried at $100{ }^{\circ} \mathrm{C}$ continually.

After coating, the graphite films and $\mathrm{Al}$ foils were cut into designed size, subsequently layered into laminates, then heated to $585^{\circ} \mathrm{C}$ in a HIP furnace and kept for $120 \mathrm{~min}$ in $50 \mathrm{MPa}$. Afterward, the composites were processed by hot rolling. The roller diameter was $250 \mathrm{~mm}$ and the rolling speed was $40 \mathrm{rpm}$. Tempering occurred at $450{ }^{\circ} \mathrm{C}$ for $20 \mathrm{~min}$ per pass.

\subsection{Characterization}

The microstructure of the composites was observed by an optical microscope (OM, Axiovert A1, Zeiss, Oberkochen, Germany) and a field emission scanning electron microscope (FE-SEM, JSM-7600F, Jeol, Tokyo, Japan). Auger electron spectrometer (AES, PHI 710, Ulvac-Phi, Chigasaki, Japan) and energy dispersion spectra (EDS) attached to the FE-SEM were applied to determine and analyze the elemental composition of the coated graphite. The TC of composite $\lambda$ was calculated by the following formula:

$$
\lambda=\alpha \cdot C_{p} \cdot \rho
$$

where $\alpha$ is the thermal diffusion coefficient of the composite measured at room temperature by a laser flash thermal analyzer (LFA-447, Netzsch, Selb, Germany). To meet the measurement requirements of thickness, the sample in size of $4 \times 10 \mathrm{~mm}$ was stacked to about $10 \mathrm{~mm} . C_{p}$ is specific heat of the composite, which was calculated according to rule of mixture:

$$
C_{p}=C_{A l} \cdot V_{A l}+C_{G r} V_{G r}
$$

where $C_{A l}, C_{G r}$ is specific heat and $V_{A l}, V_{G r}$ is the volume fraction of aluminum and graphite, respectively. Composite density was measured using the Archimedes principle.

\section{Results}

\subsection{Microstructure of Graphite and Composites}

The surface morphology and energy dispersion spectra (EDS) mapping result of Sicoated graphite are illustrated in Figure 2. The surface of coating was integrated and homogenous, and it can be seen from the EDS mapping results that the Si elements were evenly dispersed on the graphite. The EDS spectrum shows the $\mathrm{O}, \mathrm{Si}$, and $\mathrm{C}$ signals. The AES was applied to investigate the phase of the coating. As shown in Figure 2d, the valence state can be judged by the chemical shift of pattern. The Auger energy of silicon was measured to be $1608.3 \mathrm{eV}$, compared with $\mathrm{Si}(1618 \mathrm{eV}), \mathrm{SiO}_{2}(1605 \mathrm{eV})$ and $\mathrm{Si}_{3} \mathrm{~N}_{4}(1612 \mathrm{eV})$, which indicates the surface silicon has charge of plus four. Moreover, the Auger energy of oxygen was measured to be $511.4 \mathrm{eV}$, compared with $\mathrm{O}_{2}(510 \mathrm{eV})$ and $\mathrm{SiO}_{2}(502 \mathrm{eV})$. The oxygen element on the surface probably exists as an impurity, and the composition of the coating can be determined to be $\mathrm{SiC}$.

The coated graphite films and Al foils were layered into laminate, the volume of graphite was controlled at $11.1 \%$ and the initial thickness was $18 \mathrm{~mm}$. Figure 3 shows the morphology of the composites after the HIP process, where we can see the graphite film was well aligned in the composites, as expected, and no voids appeared on the interface. Afterward, the composite was machined by hot rolling, and the effects of single and total reduction were mainly compared. 


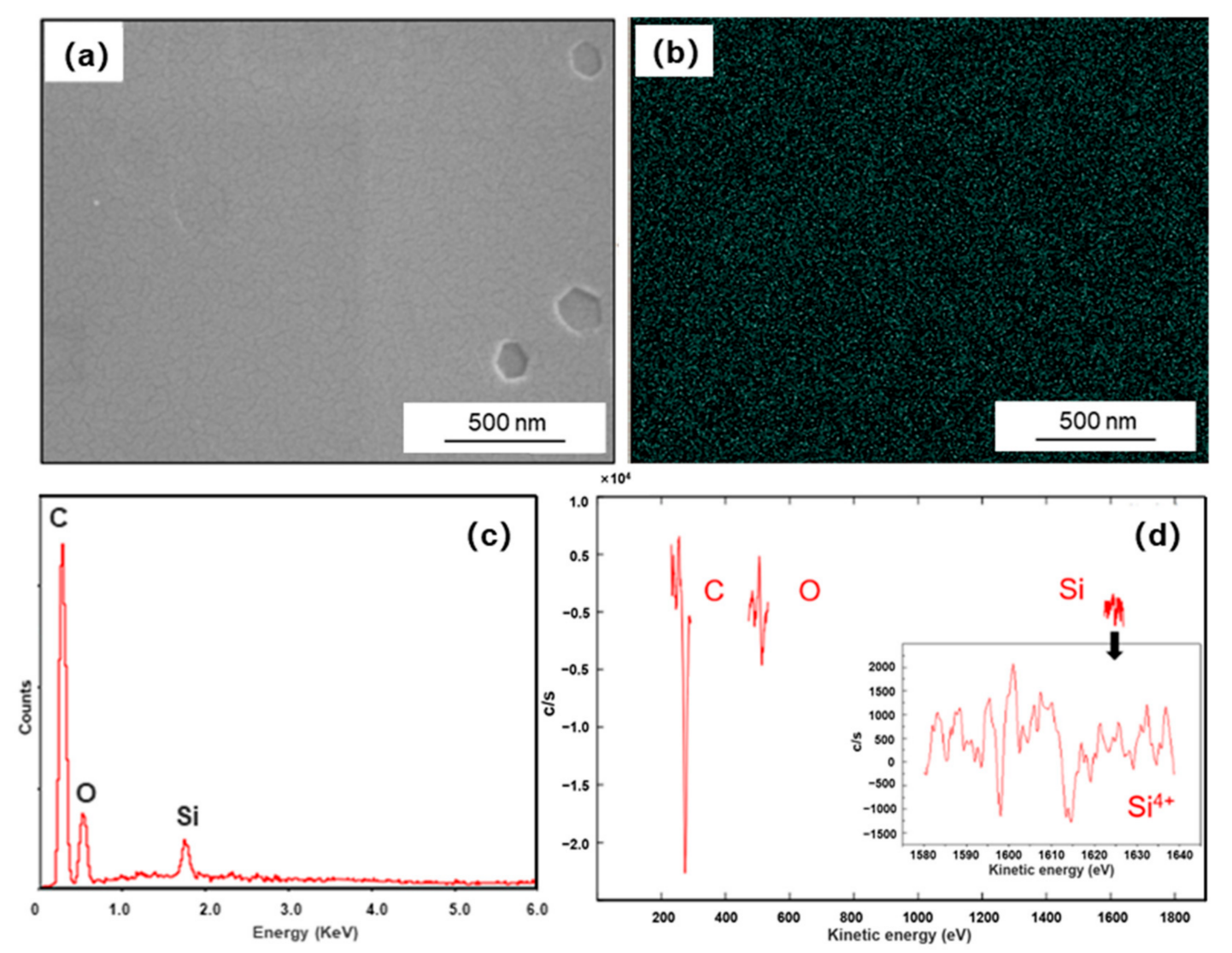

Figure 2. (a) SEM morphology of Si-coated graphite; (b) EDS mapping results of $\mathrm{Si}$; (c,d) EDS spectrum and AES pattern of the Si-coated graphite.
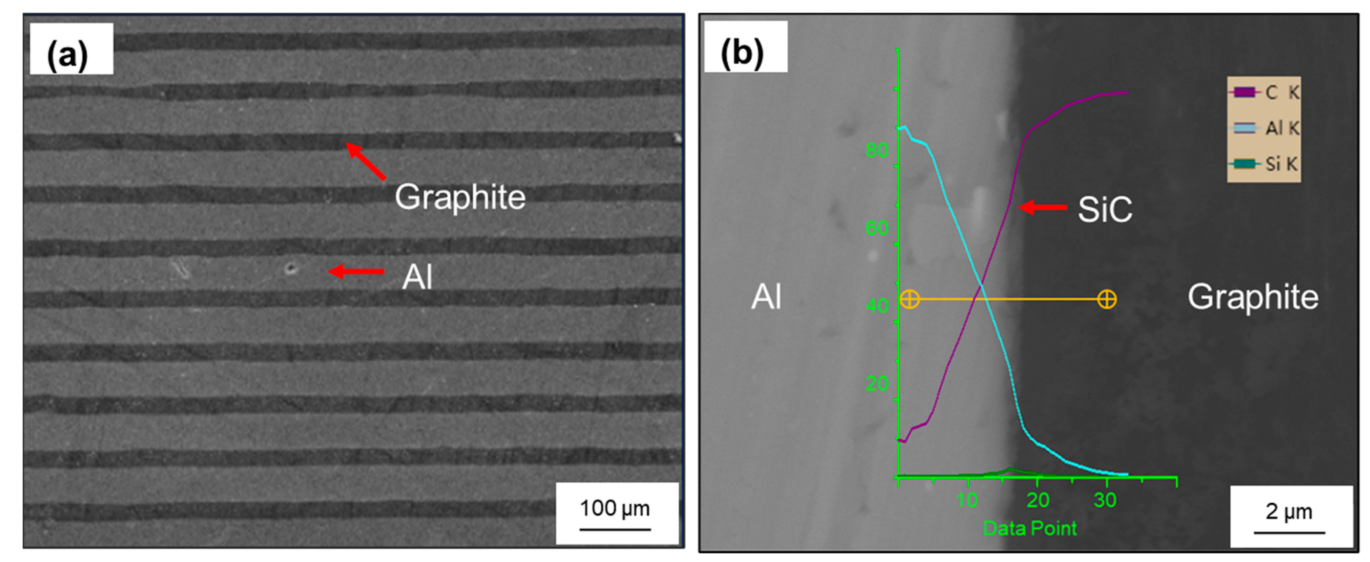

Figure 3. (a) SEM morphology of the composite after HIP process; (b) interfacial microstructure and EDS line-scan analysis.

As is well known, Al has good ductility while graphite is a brittle material, the rolling process was aiming to let graphite fracture and keep parallel orientation when the composites extending. As shown in Figure 4, comparing the influence of different total reduction $(a, b, c)$, it can be seen at the beginning of rolling, large initial thickness leads to large absolute reduction and bite angle, the deformation rate varies greatly in different regions along the height direction [21]. Thus, the main deformation modes of the composites are interlaminar extrusion and slipping. Some shear bands developed in the composite, and the fracture of graphite mainly occurs at the junction of shear bands. With the rolling processing, the reduction in thickness makes it easier for deformation to penetrate into the interior, and the deformation rate along the height direction tends to be uniform. Graphite begins to fracture along the rolling direction. Shear bands were 
flattened and new shear band no longer appears. Then, comparing the influence of different single reductions $(b, d, e)$, with the single reduction increases, passes to reach the same total reduction were also reduced, and the difference of deformation rate will result in a heterogeneous structure, and some regions still maintain a layered structure.
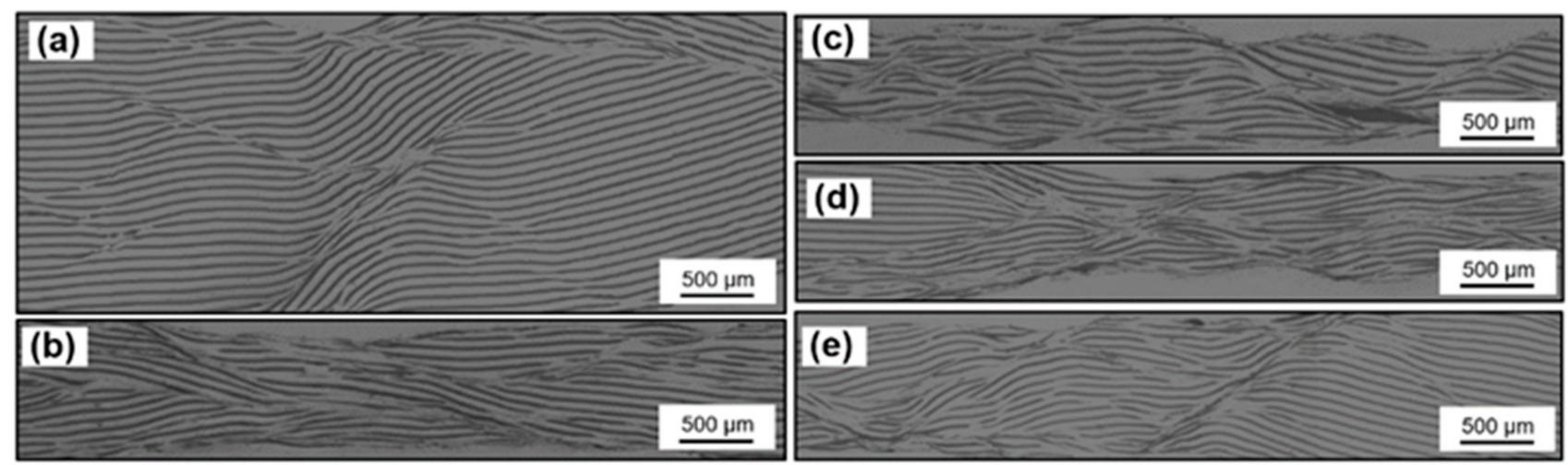

Figure 4. Morphology of composites with different single/total reduction (a) 15\%/50\%; (b) 15\%/75\%; (c) 15\%/87.5\%; (d) $20 \% / 75 \%$; (e) $30 \% / 75 \%$.

Figure 5 shows the typical deformation modes of graphite during rolling. As a multilayer material, the graphite film will also be affected and delaminated when the shear bands appear in the composites. From Figure 5 a, we can see the graphite after delamination is distributed along the shear direction. When the heat flow in parallel direction passes through the composites, due to the low axial TC of graphite, this kind of structure will inevitably have adverse effects on the TC. Besides, when the graphite fractures along the parallel direction, the internal cracks will spread out unevenly, so the fracture edge is a spindle. The size of graphite varies with the fracture degree, so it is necessary to study the $\mathrm{TC}$ of the composites under different structures.
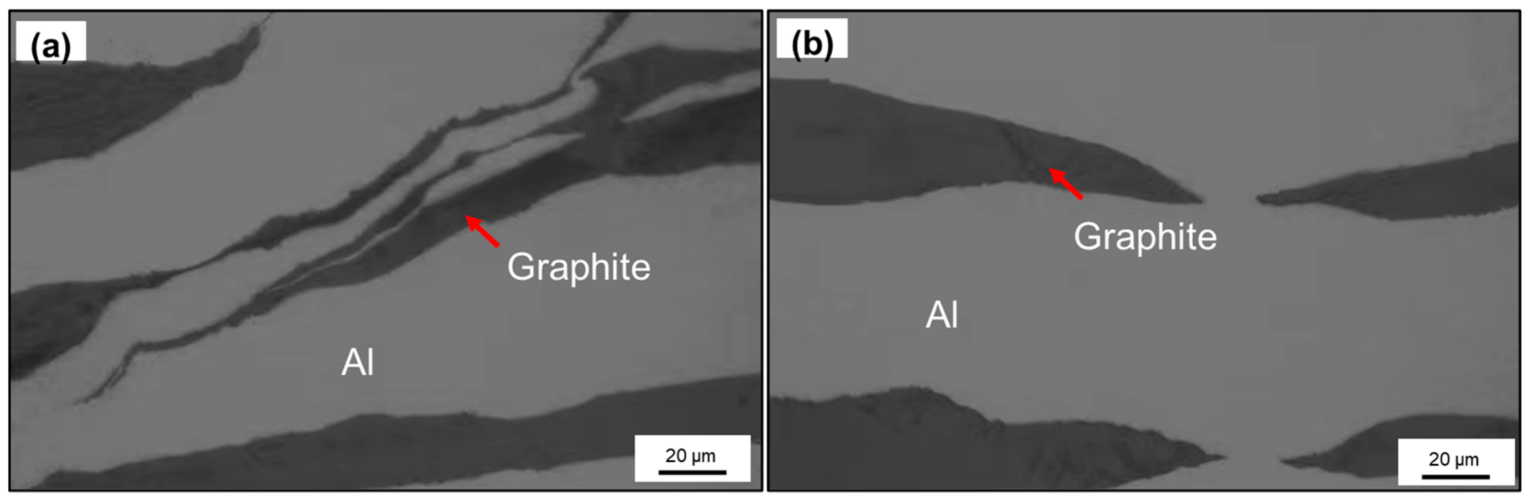

Figure 5. Typical deformation modes of graphite in rolling process: (a) slip, (b) fracture.

\subsection{Modeling and Thermal Properties}

To figure out the effect of graphite size and orientation on TC, three 12-mm samples for each process were selected and use Image-Pro Plus (IPP) to count the diameter of graphite. Besides, recent studies show that the inclination angle of the graphite will strongly weaken the in-plane TC, when the inclination angle of the reinforcement in the composite is greater than $15^{\circ}$, its in-plane TC will be lower than $90 \%$ of the theoretical value $[15,18]$. Therefore, the proportion of graphite with an inclination angle less than $15^{\circ}$ was counted to evaluate the degree of alignment (grey area in Figure 6). 

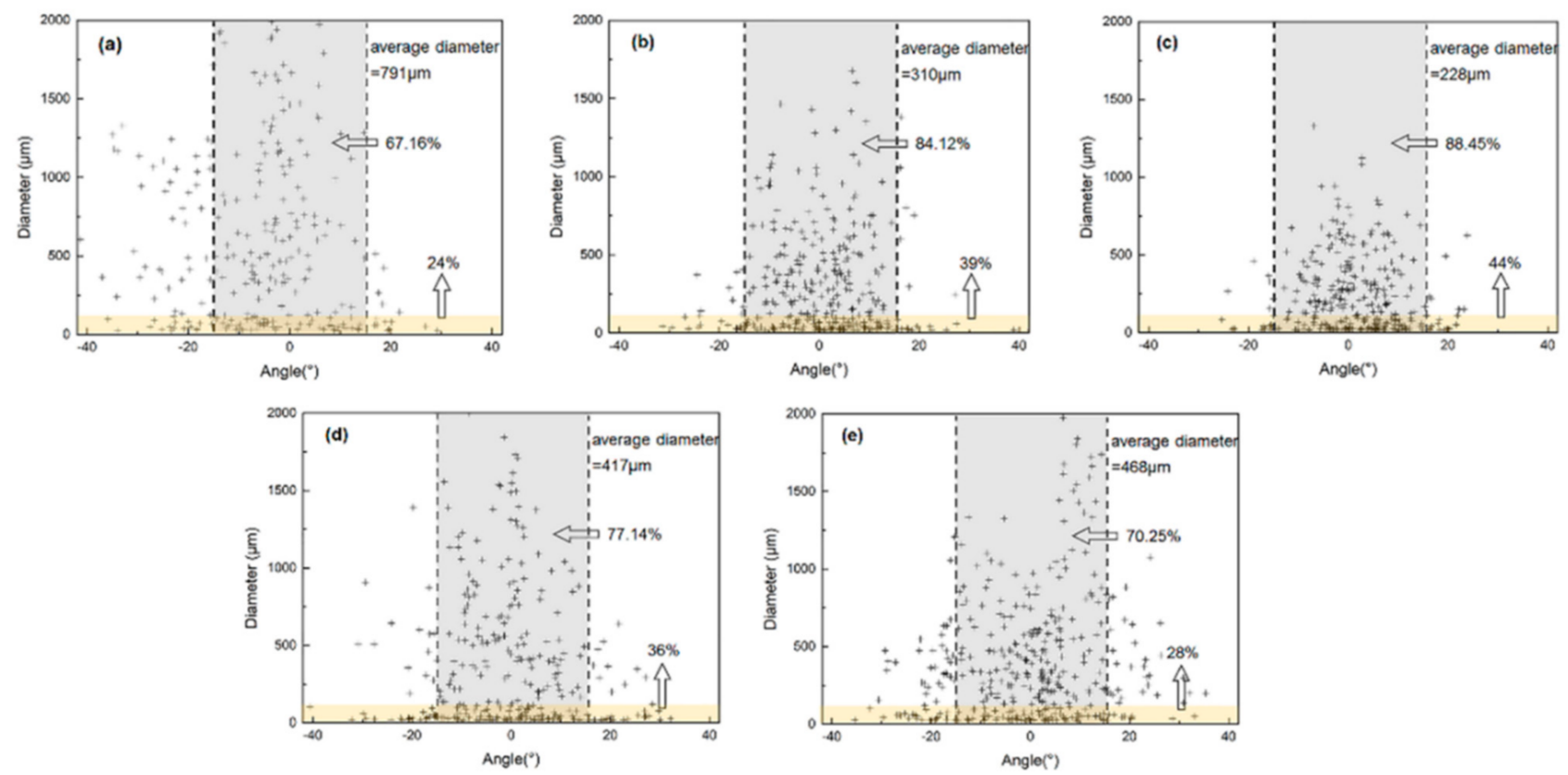

Figure 6. Inclination angle and size distribution of graphite in composite with different single/total reduction. (a) 15\%/50\%; (b) $15 \% / 75 \%$; (c) $15 \% / 87.5 \%$; (d) $20 \% / 75 \%$; (e) $30 \% / 75 \%$.

As shown in the figure, the $x$-axis and $y$-axis represent the inclination angle and diameter of graphite, respectively. With increasing in total reduction from $50 \%$ to $87.5 \%$, the average diameter of graphite decreases from $791 \mu \mathrm{m}$ to $228 \mu \mathrm{m}$ accordingly. And with the graphite gradually tends to be parallel oriented, the proportion of the graphite with inclination angle within $15^{\circ}$ increased from $67 \%$ to $88 \%$. Furthermore, the influence of different single reductions was compared $(b, d, e)$, and with single reduction increased from $15 \%$ to $30 \%$, rolling passes to reach the same total reduction were reduced. Fewer rolling passes make the size of graphite vary greatly in different areas, and the average size is also larger than the composites prepared in lower single reduction. Simultaneously, a large single reduction will cause an uneven interlayer structure. The proportion of graphite with an inclination angle less than $15^{\circ}$ decreased from $84 \%$ to $70 \%$.

To better understand the influence of graphite size on TC, a formula for calculating the effective TC was given by [22,23]:

$$
\begin{gathered}
K_{c}^{i i}=K_{s} \frac{K_{s}+L_{i i}\left(K_{c}-K_{s}\right)(1-v)+v\left(K_{c}-K_{s}\right)}{K_{s}+L_{i i}\left(K_{c}-K_{s}\right)(1-v)} \\
v=\frac{a^{2} c}{(a+\delta)^{2}(c+\delta)^{2}}
\end{gathered}
$$

where $K_{c}$ is the intrinsic TC of the graphite film, $K_{s}$ is the interfacial thermal conductance. $\delta$ is the thickness of the interface layer, while $a$ and $c$ are the short and long axes of reinforcement. In order to simply the calculation, the graphite was regarded as a disklike particle, $L_{i i}$ is the shape factor in different directions (for disklike particle, $L_{x}=L_{y}=\pi p / 4$ ), considering the thin interface layer $\left(K_{s} \rightarrow 0\right)$, and the in-plane effective TC of reinforcement was calculated in Figure 7a. It is obvious that the effective TC decreases significantly when the diameter of graphite is less than $250 \mu \mathrm{m}$, the small sized graphite is more likely to negatively affect the effective TC. Then, bringing the formula of effective TC into effective medium approach (EMA) model, the in-plane TC of composite can be expressed as:

$$
K^{*}=K_{m}\left(1+\frac{f}{\frac{\pi p}{4}(1-f)+\frac{K_{m}}{K_{c}^{i}-K_{m}}}\right)
$$


where $f$ is the volume fraction of graphite. $K_{m}$ is the TC of aluminum. Bring the average diameter and actual diameter which counted by software into the formula, the theoretical TC and the modified TC including size effects can be calculated respectively. As shown in Figure $7 b$, comparing the influence of different total reduction $(a, b, c)$, with the rolling processing, the proportion of small-sized graphite with effective TC less than $80 \%$ (yellow area in Figure 4) was increased to $44 \%$, resulting in the modified value to fall faster than the theoretical value. After excluding the influence of size, another main factor affecting the TC was the orientation of graphite. As the graphite tends to be parallel oriented, the gap between the experimental value and the modified value is also decreased. This phenomenon is especially obvious when comparing different single reductions $(b, d, e)$. The average size of the graphite fabricated by $30 \%$ single reduction was larger than that of $15 \%$ single reduction, but the TC of the reinforcement has not been effectively played. The graphite with non-parallel orientation and the irregular structure have restricted the TC of composites, which increase the gap between the experimental value and the modified value.
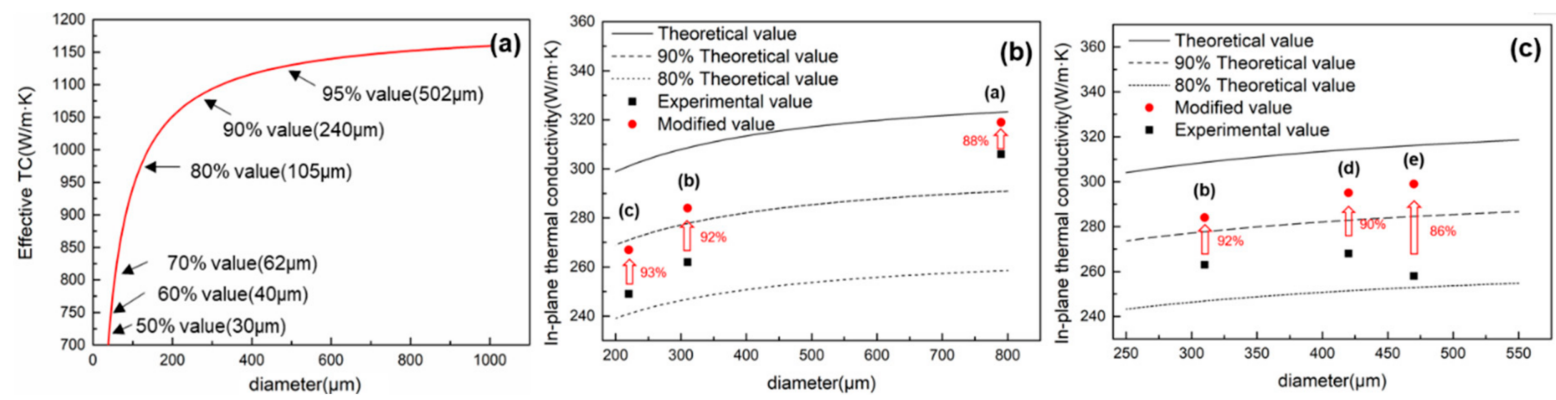

Figure 7. (a) Variety rule of the theoretical effective TC of graphite with diameter; (b,c) In-plane TC of composite with different single/total reduction.

\subsection{Optimization of the Process}

The analysis above shows the main factors influencing the TC are the size and orientation of graphite, large absolute reduction is likely to cause the uneven structure, while too many rolling passes will increase the proportion of small-sized graphite. In order to further study the influence of absolute reduction and thickness of rolled piece on metal flow during the rolling process, ignore the influence of the graphite, the internal metal flow of $40 \mathrm{~mm}$ and $20 \mathrm{~mm}$ thick aluminum plates under 30\%/15\% single reduction was simulated by Abaqus, the roller size and rolling speed are the same as the experiment, and the friction coefficient between roller and aluminum plates is set to 0.3.

As shown in Figure 8, when the rolled piece is thick, the large absolute reduction leads to large stress angle and long contact arc, which results in a large velocity gradient in the deformation zone, this may be the main reason for interlaminar shear deformation during rolling. Besides, the metal flow rate along the height direction is very uneven in the deformation area, but tends to be consistent in the exit area, which will also lead to excessive differences in the degree of deformation of the rolled piece. By reducing the single reduction to $15 \%$, the rolled piece is mainly affected by the friction of the roller, the deformation cannot penetrate into the interior, and the metal flow rate between the surface layer and the inner layer is quite different. As the thickness of rolled piece decreases to 20 $\mathrm{mm}$, with the decrease in absolute reduction and stress angle, the area of velocity gradient decreases correspondingly, further reducing the single reduction. Thus, the metal flow rate in different areas of the rolled piece tends to be uniform.

Therefore, an optimal scheme is proposed as follows: (1) By adding the extra layer on both sides of the rolled piece, so that the adverse effect caused by the difference of metal flow rate between the surface layer and the inner layer can be reduced; (2) Reduce the thickness of rolled piece. 
The composite with initial thickness of $2 \mathrm{~mm}$ and $20 \%$ volume of graphite was prepared, and the total thickness was increased up to $8 \mathrm{~mm}, 12 \mathrm{~mm}$, and $16 \mathrm{~mm}$ by adding the aluminum layer. The total reduction is $75 \%$ and the single reduction is $15 \%$. After rolling, the surplus aluminum on the material surface was milled off. As shown in Figure 7. Obviously, the orientation of graphite was improved by reducing the thickness of rolled piece, however, the interlayer structure was still slightly affected by the velocity difference between surface layer and the inner layer, by further increasing the thickness of the additional layer to $16 \mathrm{~mm}$, the proportion of graphite with inclination angle less than $15^{\circ}$ can reach up to $95 \%$. Furthermore, when the thickness of a rolled piece is $8 \mathrm{~mm}$, the elongation is also very low under the same total reduction, which limits the fracture of graphite. The average size of graphite counted by IPP is $612 \mu \mathrm{m}$. With the increase in thickness, the average size of graphite was reduced to $557 \mu \mathrm{m}$ and $439 \mu \mathrm{m}$, respectively. As shown in Figure $9 d$, after process optimization, the in-plane TC all approach or exceed $90 \%$ of the theoretical value, and mainly being affected by the orientation of graphite, when the whole graphite tends to be parallel oriented, the experimental value is $354 \mathrm{~W} / \mathrm{m} \cdot \mathrm{K}$, which can reach $97.8 \%$ of the modified value.
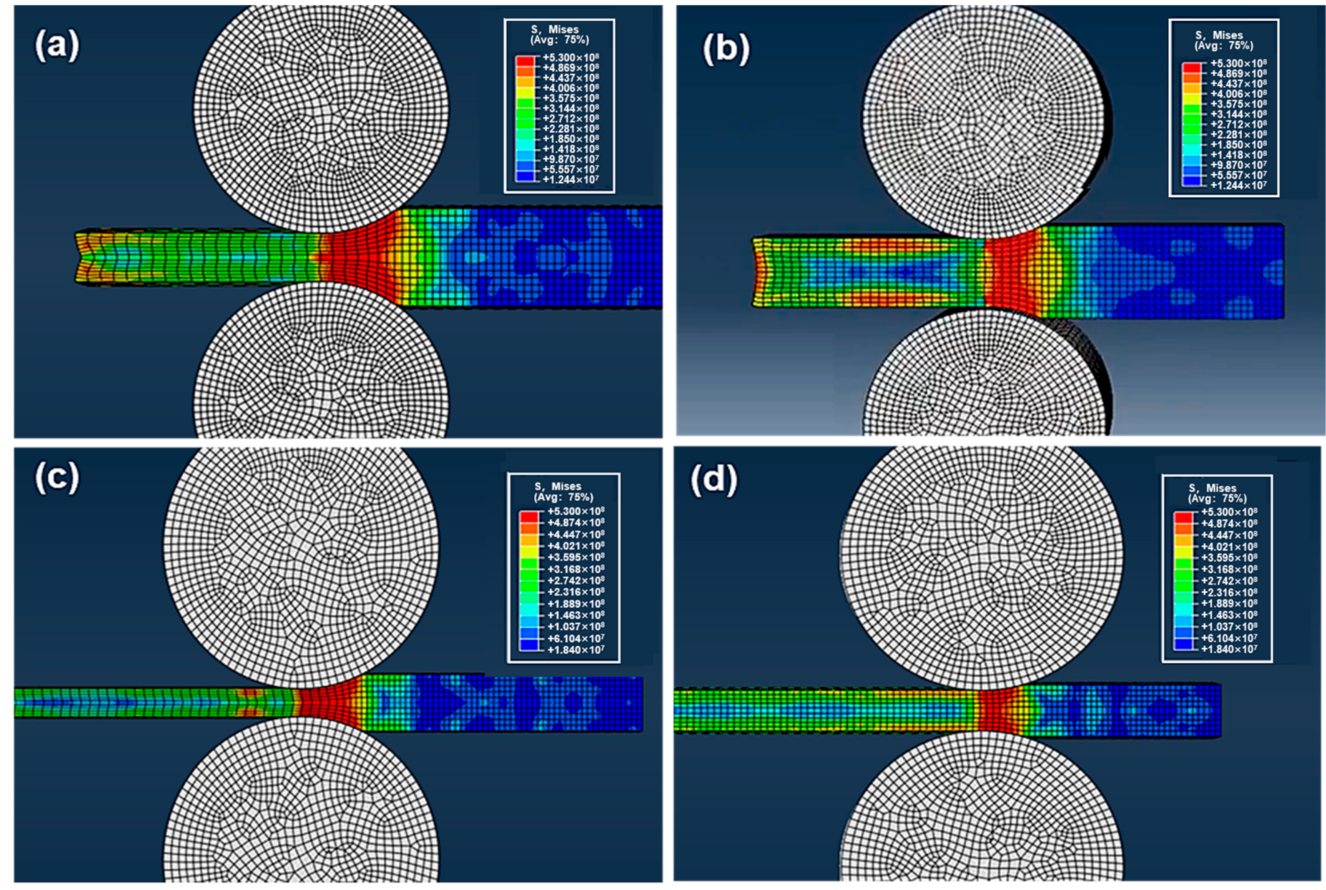

Figure 8. Simulation of the metal flow in rolling with different thickness aluminum plates and single reduction (a) $40 \mathrm{~mm}$, $30 \%$; (b) $40 \mathrm{~mm}, 15 \%$; (c) $20 \mathrm{~mm}, 30 \%$; (d) $20 \mathrm{~mm}, 15 \%$.
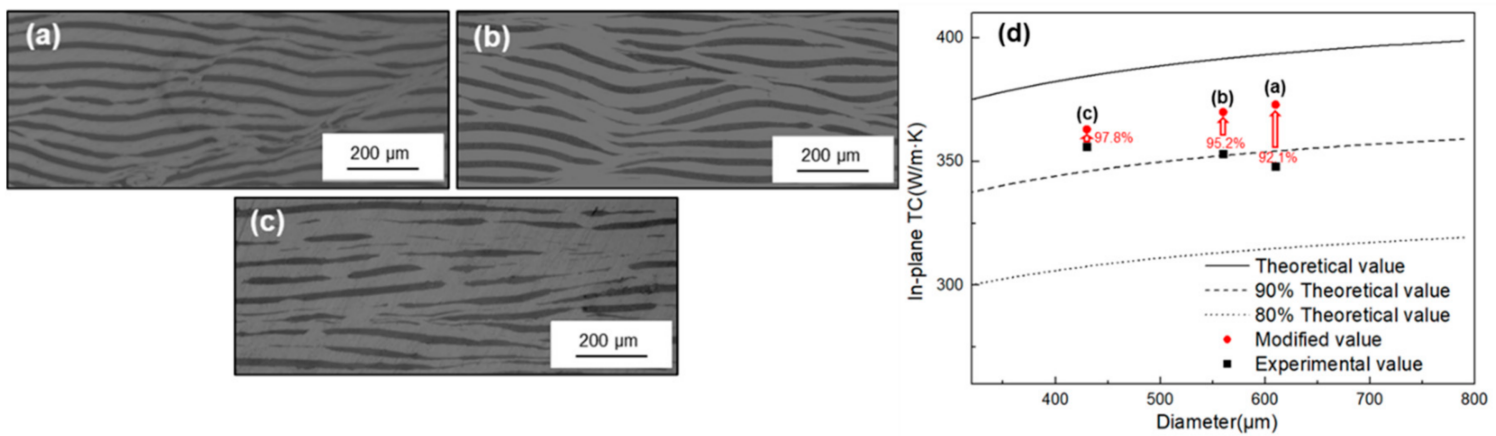

Figure 9. Morphology of composites with different initial thickness (a) $6 \mathrm{~mm}$; (b) $8 \mathrm{~mm}$; (c) $12 \mathrm{~mm}$; (d) In-plane TC of (a-c). 
Figure 10 shows the tensile fracture morphology of composites with different total thickness. Normally, the strength of graphite is much lower than that of $\mathrm{Al}$ matrix, which leads to cracks preferentially generated on the graphite. In addition, affected by the different microstructure of the composites, the fracture also presents different characteristics. As shown in Figure 10a, the fracture surface is an inclined plane, and there is peeling between graphite and matrix in some areas. This is due to the shear band in the composite, when the composite was subjected to a horizontal load, the force will directly act on the interface between graphite and Al. Besides, the graphite film is composed of many graphite layers, the bonding between the layers is very weak, so the main failure mode of graphite is delamination, and the cracks will rapidly expend into the matrix, jagged tear can be observed in partial fracture region, the fracture surface is very uneven. Therefore, the tensile strength of the composites is also relatively lower.
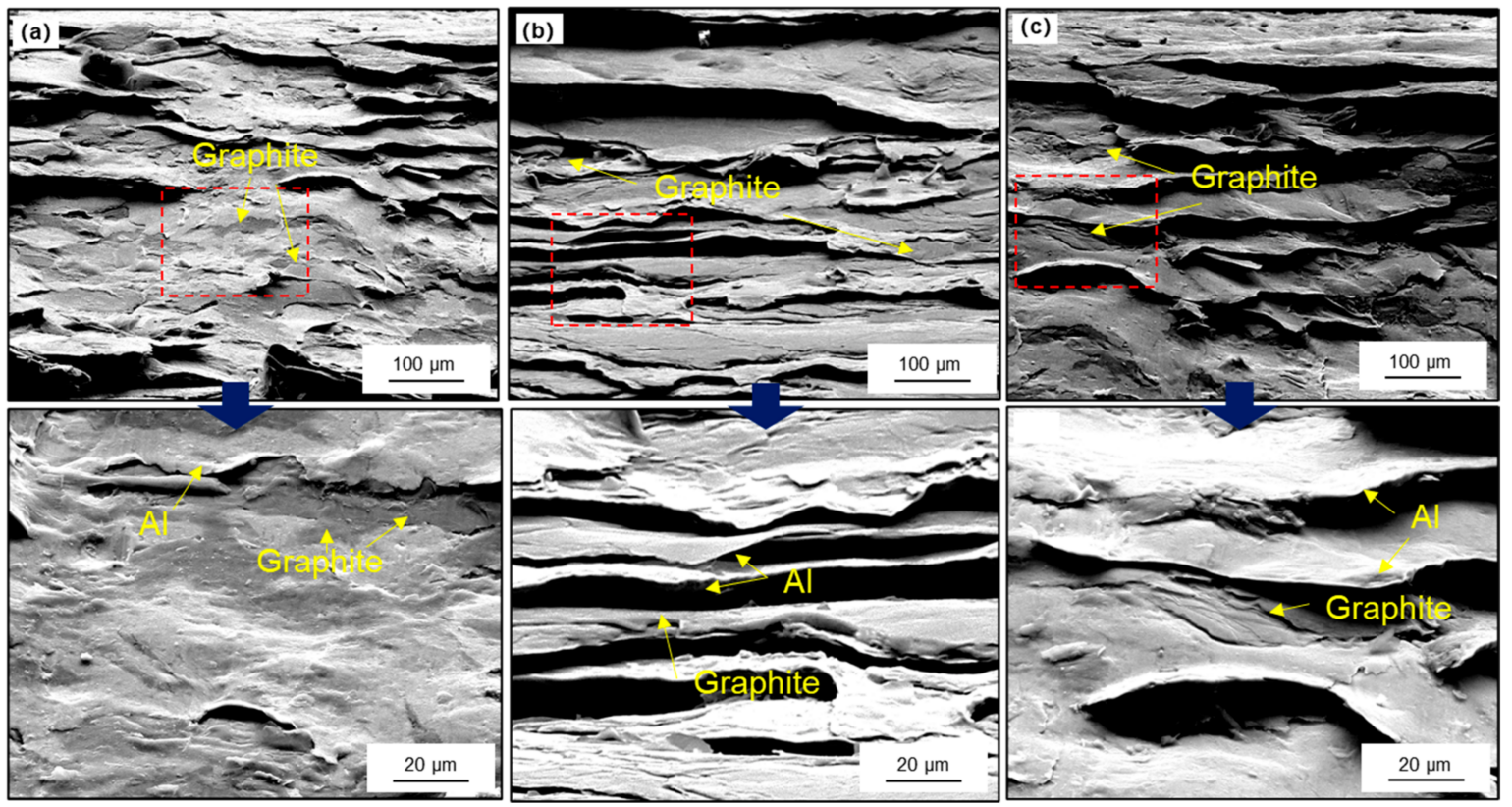

Figure 10. Tensile fracture morphology of composites with different total thickness (a) $6 \mathrm{~mm}$; (b) $8 \mathrm{~mm}$; (c) $12 \mathrm{~mm}$.

When the graphite tends to be parallel orientated, the main failure mode of graphite is transformed into horizontal fracture. However, due to the large size of graphite, the effect of the $\mathrm{Al}$ matrix constraint is limited. As the average size of graphite further decreases, the crack propagation distance in the graphite can be more effectively constrained by the $\mathrm{Al}$ matrix. As shown in Figure 10c, the fracture surface is characterized as a layered distribution. The fracture of the graphite and the necking of the surrounding $\mathrm{Al}$ matrix can be observed, which indicates that the reinforcement effect of the matrix is effectively exerted, and the tensile strength of the composites was improved correspondingly. The properties of the composites prepared with different initial thickness are listed in Table 1.

Table 1. Properties of composites with different initial thickness.

\begin{tabular}{cccc}
\hline $\begin{array}{c}\text { Total Thickness } \\
(\mathbf{m m})\end{array}$ & $\begin{array}{c}\text { Average Size } \\
(\boldsymbol{\mu \mathbf { m } )}\end{array}$ & $\begin{array}{c}\text { Tensile Strength } \\
(\mathbf{M P a})\end{array}$ & $\begin{array}{c}\text { In-Plane TC } \\
(\mathbf{W} / \mathbf{m} \cdot \mathbf{K})\end{array}$ \\
\hline 8 & 612 & 56 & 343 \\
12 & 557 & 63 & 351 \\
16 & 439 & 77 & 354 \\
\hline
\end{tabular}

Figure 11 shows the comparison of the in-plane TC of the composites fabricated in this study with that of other studies, in which we can see that the composites prepared in 
this study can achieve higher TC under the same graphite content. This is probably due to the higher intrinsic TC of graphite film compared with other carbon materials. Moreover, through optimizing the rolling process, the graphite can fracture and maintain a parallel orientation in the composite. This discontinuous configuration can make the composite keep a certain mechanical property. Moreover, the composite fabricated in this study can be as thin as $0.6 \mathrm{~mm}$. This near-net-forming process can directly meet the thickness requirements for electronic packaging and avoids the exposure of graphite to the surface due to secondary processing, which is promising to provide a novel approach to promote the application for high $\mathrm{TC} \mathrm{C} / \mathrm{Al}$ composites.

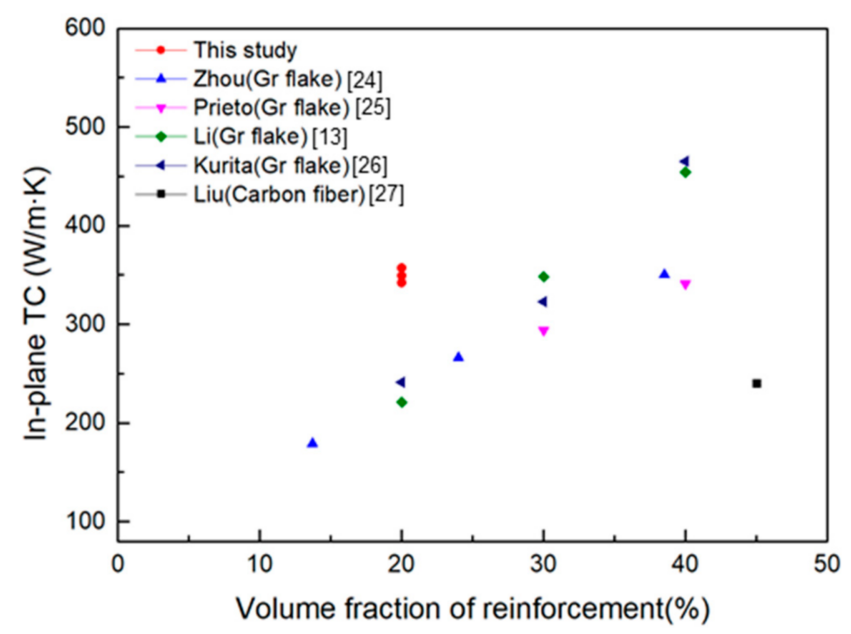

Figure 11. In-plane $\mathrm{TC}$ compared with other $\mathrm{C} / \mathrm{Al}$ composites fabricated in the reference [24-27].

\section{Conclusions}

In this study, a novel preparation process for Graphite/Al composites with high TC was proposed. This was achieved by fabricating the aluminum foil and graphite film with ultra-high TC into laminate material, then changing the composite into a discontinuous configuration via a rolling process. The result reveals that both single reduction and total reduction have a significant influence on the size and orientation of the graphite. Through process optimization, the fractured and well oriented graphite film can make the composite have high TC while maintain certain mechanical properties. When the volume fraction of graphite is $20 \%$, the in-plane TC of the composite can reach as high as $354 \mathrm{~W} / \mathrm{m} \cdot \mathrm{K}$, while the tensile strength is $77 \mathrm{MPa}$. Moreover, it is expected that the properties of the composites can be further improved by adjusting the graphite volume and adopting an aluminum alloy matrix with higher strength.

Author Contributions: Conceptualization, H.J., J.F., and Y.L.; methodology, H.J., J.F., and Y.L.; validation, S.W.; investigation, H.J., S.W., and Y.L.; writing—original draft, H.J.; writing-review \& editing, H.J., Y.Z., and J.F.; formal analysis, Y.Z. and J.N.; resources, J.F., J.N., and Y.L.; funding acquisition, Y.L and J.N.; supervision, J.F.; project administration J.F. All authors have read and agreed to the published version of the manuscript.

Funding: This work was supported by National Key R\&D Program of China (No.2018YFB0704401), National Key R\&D Program of China (No.2017YFB0703104).

Institutional Review Board Statement: Not applicable.

Informed Consent Statement: Not applicable.

Data Availability Statement: Data is contained within the article.

Conflicts of Interest: The authors declare no conflict of interest. 


\section{References}

1. Mallik, S.; Ekere, N.; Best, C.; Bhatti, R. Investigation of thermal management materials for automotive electronic control units. Appl. Therm. Eng. 2011, 31, 355-362. [CrossRef]

2. Yuan, G.; Li, X.; Dong, Z.; Westwood, A.; Cui, Z.; Ye, C.; Du, H.; Kang, F. Graphite blocks with preferred orientation and high thermal conductivity. Carbon 2012, 50, 82-175. [CrossRef]

3. Qu, X.; Zhang, L.; Wu, M.; Ren, S. Review of metal matrix composites with high thermal conductivity for thermal management applications. Prog. Nat. Sci. 2011, 21, 189-197. [CrossRef]

4. Huang, Y.; Ouyang, Q.; Zhang, D.; Zhu, J.; Li, R.; Yu, H. Carbon Materials Reinforced Aluminum Composites: A Review. Acta Metall. Sin. (Engl. Lett.) 2014, 27, 775-786. [CrossRef]

5. Kim, Y.S.; Kim, J.K.; Jeon, E.S. Effect of the Compounding Conditions of Polyamide 6, Carbon Fiber, and $\mathrm{Al}_{2} \mathrm{O}_{3}$ on the $\mathrm{Mechanical}$ and Thermal Properties of the Composite Polymer. Materials 2019, 12, 3047. [CrossRef] [PubMed]

6. Zhang, H.; Chao, M.; Zhang, H.; Tang, A.; Ren, B.; He, X. Microstructure and thermal properties of copper matrix composites reinforced by chromium-coated discontinuous graphite fibers. Appl. Therm. Eng. 2014, 73, 739-744. [CrossRef]

7. Monje, I.E.; Louis, E.; Molina, J.M. Optimizing thermal conductivity in gas-pressure infiltrated aluminum/diamond composites by precise processing control. Compos. Part A Appl. Sci. Manuf. 2013, 48, 9-14. [CrossRef]

8. Che, Z.; Li, J.; Wang, Q.; Wang, L.; Zhang, H.; Zhang, Y.; Wang, X.; Wang, J.; Kim, J.M. The formation of atomic-level interfacial layer and its effect on thermal conductivity of W-coated diamond particles reinforced $\mathrm{Al}$ matrix composites. Compos. Part A Appl. Sci. Manuf. 2018, 107A, 164-170. [CrossRef]

9. Athanasiou, M.; Samartzis, N.; Sygellou, L.; Dracopoulos, V.; Yannopoulos, S.N. High-quality laser-assisted biomass-based turbostratic graphene for high-performance supercapacitors. Carbon 2020, 172, 750-761. [CrossRef]

10. Abbasi, S.M.; Ahmadi, H.; Khalaj, G.; Ghasemi, B. Microstructure and mechanical properties of a metakaolinite-based geopolymer nanocomposite reinforced with carbon nanotubes. Ceram. Int. 2016, 42, 15171-15176. [CrossRef]

11. Han, X.; Huang, Y.; Zhou, S.; Sun, X.; Peng, X.; Chen, X. Effects of graphene content on thermal and mechanical properties of chromium-coated graphite flakes/Si/Al composites. J. Mater. Sci. 2017, 29, 4179-4189. [CrossRef]

12. Li, D.; Wang, C.; Su, Y.; Zhang, D.; Ouyang, Q. Governing the inclination angle of graphite flakes in the graphite flake/al composites by controlling the al particle size via flake powder metallurgy. Acta Metall. Sin. 2020, 1-10. [CrossRef]

13. Li, W.; Liu, Y.; Wu, G. Preparation of graphite flakes/Al with preferred orientation and high thermal conductivity by squeeze casting. Carbon 2015, 95, 545-551. [CrossRef]

14. Xue, C.; Bai, H.; Tao, P.; Wang, J.; Jiang, N.; Wang, S. Thermal conductivity and mechanical properties of flake graphite/Al composite with a SiC nano-layer on graphite surface. Mater. Des. 2016, 108, 250-258. [CrossRef]

15. Molina, J.M.; Louis, E. Anisotropy in thermal conductivity of graphite flakes-SiCp/matrix composites: Implications in heat sinking design for thermal management applications. Mater. Charact. 2015, 109, 107-115. [CrossRef]

16. Huang, Y.; Ouyang, Q.; Guo, Q.; Guo, X.; Zhang, G.; Zhang, D. Graphite film/aluminum laminate composites with ultrahigh thermal conductivity for thermal management applications. Mater. Des. 2016, 90, 508-515. [CrossRef]

17. Huang, Y.; Su, Y.; Li, S.; Ouyang, Q.; Zhang, G.; Zhang, L.; Zhang, D. Fabrication of graphite film/aluminum composites by vacuum hot pressing: Process optimization and thermal conductivity. Compos. Part B Eng. 2016, 107, 43-50. [CrossRef]

18. Liu, X.; Wang, W.; Wang, D.; Xiao, B.; Ni, D.; Chen, L.; Ma, Z. Effect of graphite flake size on the strength and thermal conductivity of graphite flakes/Al composites. Acta Metall. Sin. 2017, 53, 869-878.

19. Monazzah, A.H.; Pouraliakbar, H.; Bagheri, R.; Reihani, S. Al-Mg-Si/SiC laminated composites: Fabrication, architectural characteristics, toughness, damage tolerance, fracture mechanisms. Compos. Part B Eng. 2017, 125, 49-70. [CrossRef]

20. Monazzah, A.H.; Pouraliakbar, H.; Bagheri, R.; Reihani, S. Toughness behavior in roll-bonded laminates based on AA6061/SiCp composites. Mater. Sci. Eng. A Struct. 2014, 598, 162-173. [CrossRef]

21. Yang, D.; Cizek, P.; Hodgson, P.; Wen, C. Ultrafine equiaxed-grain Ti/Al composite produced by accumulative roll bonding. Scr Mater. 2010, 62, 321-324. [CrossRef]

22. Nan, C.; Birringer, R.; Clarke, D.R.; Gleiter, H. Effective thermal conductivity of particulate composites with interfacial thermal resistance. J. Appl. Phys. 1997, 81, 6692-6699. [CrossRef]

23. Nan, C.; Weng, G. Influence of polarization orientation on the effective properties of piezoelectric composites. J. Appl. Phys. 2000, 88, 416-423. [CrossRef]

24. Prieto, R.; Molina, J.M.; Narciso, J.; Louis, E. Thermal conductivity of graphite flakes-SiC particles/metal composites. Compos. Part A Appl. Sci. Manuf. 2011, 42, 1970-1977. [CrossRef]

25. Zhou, C.; Ji, G.; Chen, Z.; Wang, M.; Addad, A.; Schryvers, D.; Wang, H. Fabrication, interface characterization and modeling of oriented graphite flakes/Si/Al composites for thermal management applications. Mater. Des. 2014, 63, 719-728. [CrossRef]

26. Kurita, H.; Miyazaki, T.; Kawasaki, A.; Lu, Y.; Silvain, J.F. Interfacial microstructure of graphite flake reinforced aluminum matrix composites fabricated via hot pressing. Compos. Part A Appl. Sci. Manuf. 2015, 73, 125-131. [CrossRef]

27. Liu, T.; He, X.; Liu, Q.; Ren, S.; Zhang, L.; Qu, X. Preparation and Thermal Conductivity of Spark Plasma Sintered Aluminum Matrix Composites Reinforced with Titanium-Coated Graphite Fibers. Adv. Eng. Mater. 2015, 17, 502-511. [CrossRef] 